\title{
Glucans as New Anticancer Agents
}

\author{
PETR SIMA $^{1}$, JOSEF RICHTER ${ }^{2}$ and VACLAV VETVICKA ${ }^{3}$ \\ ${ }^{1}$ Department of Immunology, Institute of Microbiology, Prague, Czech Republic; \\ ${ }^{2}$ Institute of Public Health in Usti nad Labem, Ústí nad Labem, Czech Republic; \\ ${ }^{3}$ Department of Pathology and Laboratory Medicine, University of Louisville, Louisville, KY, U.S.A.
}

\begin{abstract}
For decades, glucans have been studied for their biological and immunological activities. The scientific community has mainly focused on immune reactions, but other areas, such as cholesterol levels and diabetic retinopathy, have shown the positive effects of glucan supplementation. However, the majority of studies focused on possible cancer suppression, where glucans showed clear and significant effects on numerous types of cancers, leading not only to clinical trials, but to approval as an official drug. The aim of this review is to describe the current knowledge of this field.
\end{abstract}

The use of natural immunomodulators remains one of the primary interests of both the general public and health professionals. In this review we focus on the up-to-date knowledge on the use of glucans in medicine.

Throughout history, people have been aware that some mushrooms have healing properties. An ancient text found in India, written more than 5,000 years ago, focuses on the medicinal effects of mushrooms, and a Japanese legend described monkeys without serious diseases after feasting on the mushroom Lentinula edodes. Much later, Japanese interest in chemical components was based on this legend, resulting in development of lentinan. African shamans and Native Americans have used similar knowledge (1).

$\beta-1,3-D-G l u c a n s$ (hereafter referred to as glucans) are natural molecules able to significantly improve our health. They represent highly conserved structures often named pathogen-associated molecular patterns [for review, see Zipfel and Robatzek (2)]. There are many chemically heterogeneous polymers of beta glucose differing in glycosidic bond position.

Correspondence to: Vaclav Vetvicka, University of Louisville, Department of Pathology, 511 S. Floyd, Louisville, KY 40292, U.S.A. Tel: +1 5028521612, Fax: +1 5028521177, e-mail: vaclav.vetvicka@louisville.edu

Key Words: Glucan, cancer, immunity, nutrition, fiber, review.
Some have a linear molecule with $(1 \rightarrow 3)$-beta-D-glycosidic linkages, and some have a branched one, with side chains bound by $(1 \rightarrow 6)$-beta-D-glycosidic linkages. All glucans may cause nearly identical immunological responses within multicellular organisms regardless of their origin, structure and water solubility. In addition, they elicit numerous other physiological effects and, therefore, are generally classified as immunomodulators within a large group of so-called biological response modifiers (3-6). Glucans as structural components of fungal, yeast, and seaweed cells are ranked among immuno-stimulants such as endotoxin of Gramnegative microorganisms, muramyldipeptide, zymosan, and polynucleotides.

A proper history of polysaccharides considered to be immunomodulators can be traced back almost 80 years when Shear and Turner described a polysaccharide isolated from Serratia marcescens that sometimes caused tumor necrosis (7). In Europe and Northern America, the investigation of polysaccharides in medicine started in the 1960s and 1970s. It was originally based on the immunomodulatory effects of zymosan, which was isolated by Pillemer and Ecker from baker's yeast, Saccharomyces cerevisiae (8). Zymosan is a mixture of various polysaccharides in which the glucan-rich fraction exerts the main biological activity (8). Various types of glucans have now been isolated which differ in molecular weight, branching, and biological activities. It is important to note that some of these glucans have shown no or very low biological activity (9).

Initially, most research studies on glucans focused on the effects on the murine immune system. However, subsequent research has clearly established that glucan has strong immunostimulatory effects in a wide variety of species, including earthworms, bees, shrimp, fish, chicken, rats, rabbits, guinea pigs, sheep, goats, pigs, cows, monkeys, and humans (10-12). It has been concluded that glucans represent unique immunostimulants that are active in every species; it is one of the few immunostimulants active across the evolutionary spectrum (13). Some surprising experiments 
have even demonstrated that glucan supports plant protection against disease $(14,15)$.

Glucans are considered strong activators of cellular immunity, with macrophages being their most important targets. Originally, glucans were established as playing a role in protection against infection. Since the original study published more than 35 years ago showing possible cancer suppression (16), the antitumor activity of glucans has been established. In fact, numerous animal and human studies have shown glucans to have remarkable activity against a wide variety of tumors (17-21), leading to use of glucan as an official drug (22). Studies focused on mechanism of action have revealed that glucans have strong synergy with naturally occurring anticancer antibodies $(19,23,24)$.

Glucans have pleiotropic effects on individual branches of the defense reactions. The individual components of the immune system affected by glucans are summarized in Figure 1. Glucans are recognized by various receptors present on membranes of cells such as macrophages, monocytes, dendritic cells, and natural killer cells. The most important receptors are dectin-1 and complement receptor 3 (CR3; CD11b/CD18); additional receptors include toll-like receptor 2 (TOLL2), lactosylceramides, and the scavenger receptor family [for review, see Vetvicka (25)]. Upon binding, various biological processes occur, including direct receptor activation and cellular pathway activation (25).

\section{Glucans in Clinical Use}

In addition to immune reactions, glucans also act as dietary fiber. In this role, they may positively influence numerous widespread noncommunicable diseases such as cardiovascular disease, cancer, and diabetes type 2 [for review see Brown, et al. (26)]. Glucans fulfill the modern definition of dietary fiber (27), which now includes all types of carbohydrates that resist enzymatic digestion in the small intestine and are not absorbed there $(28,29)$. Similarly to other types of dietary fiber, glucans can bind bile acids, thus lowering blood cholesterol (30). Glucans also possess the ability to affect phosphorylation of adenosine monophosphate-activated protein kinase, which regulates energy exchange (31).

\section{Glucans and Cancer}

Since the 1970s, several articles reported that glucan administration caused significant stimulation of phagocytic activity of the reticuloendothelial system with subsequent enhancement of host defense mechanisms (32, 33). Augmentation of proliferative activity and phagocytic function of granulocytes, monocytes, dendritic cells, and macrophages and stimulation of cytokine production (such as interleukin-1, 2 , and -6$)$ was confirmed $(34,35)$. Increased production of these cytokines subsequently stimulates immune effector cells,

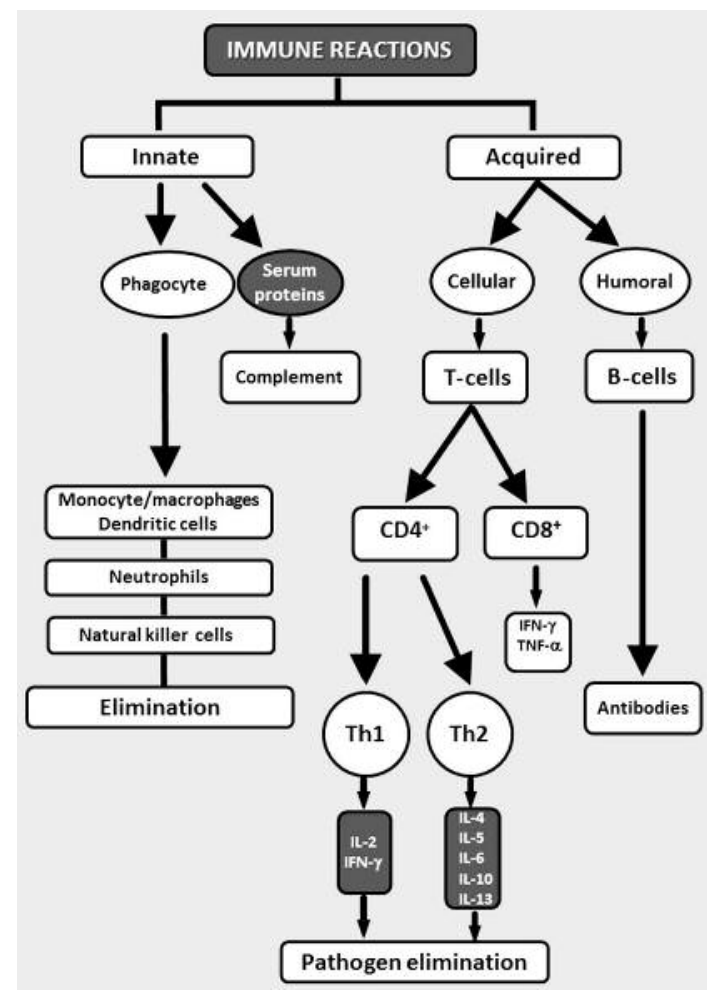

Figure 1. Various aspects of cellular and humoral branches of immune reactions. Reactions known to be influenced by glucans are represented in white; reactions where glucans have no confirmed effects are shown in black. IFN- $\gamma$ : Interferon gamma, TNF- $\alpha$ : tumor necrosis factor alpha, $\mathrm{CD}^{+}$: CD4-positive lymphocytes, $C D 8^{+}$: CD8-positive lymphocytes, Th1: T-helper 1 cells, Th2: T-helper 2 cells, IL: interleukin.

resulting in increased anti-infectious and mainly anticancer immunity $(22,36)$. Besides these direct effects, glucans scavenge free radicals, which are the main initiators of carcinogenesis $(16,37)$. Japanese scientists focused traditionally on mushroom-derived glucans and their effects on antitumor immunity $(38,39)$. Studies with immunomodulatory glucans from L. edodes resulted in approval of lentinan as an official drug in Japan. Many types of cancers have been shown to be sensitive to glucan therapy as demonstrated in both animal (40) and human models (41). Examples of the main types of glucans used in the form of dietary supplements for the support of treatment of various types of cancer are summarized in Table I.

\section{Additional Effects}

Several additional important effects of glucans were later demonstrated including hypoglycemic effects, reduction of cholesterol level (42), and improvements of ulcerative colitis. There is a large amount of data on the health and nutritional benefits of glucans, proposing their use as novel 

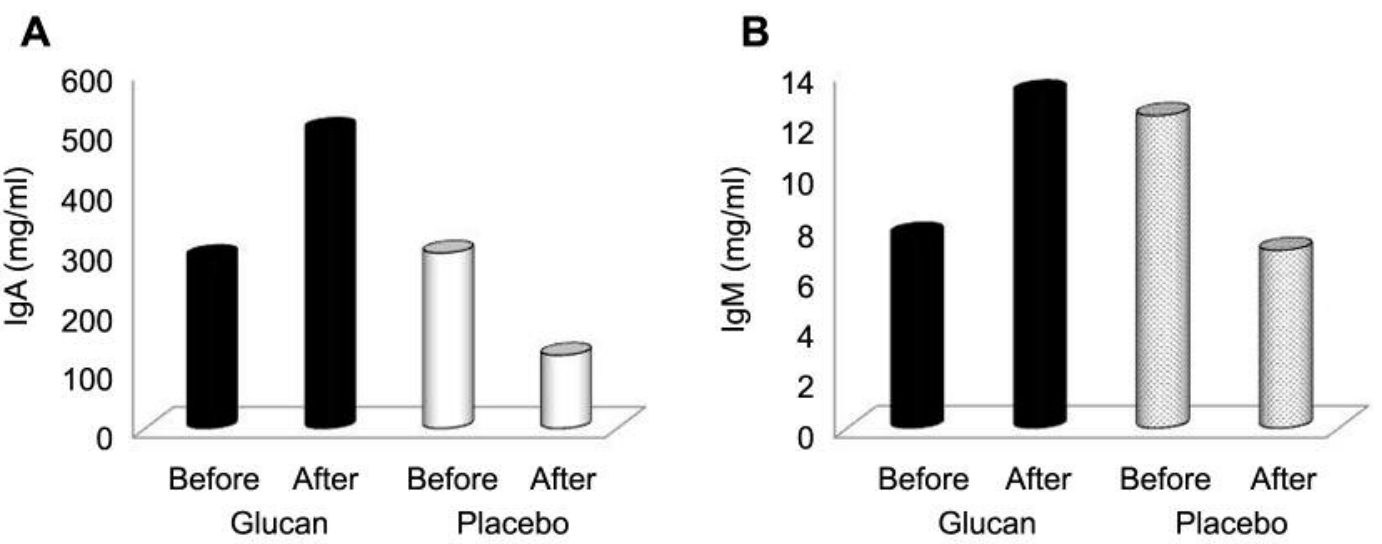

Figure 2. Salivary IgA (A) and IgM (B) in children with chronic respiratory problems at the start and end of 30-day supplementation with glucan or placebo.

Table I. Glucans used in treatment of cancer.

\begin{tabular}{ll}
\hline Cancer & Betaglucan/origin \\
\hline Gastric & Schizophyllan/ \\
& Schizophyllum commune \\
Esophageal cancer & Lentinan/Lentinula edodes \\
Colorectal cancer & Lentinan/Lentinula edodes \\
& Lentinan/Lentinula edodes \\
Hepatocellular cancer & Agaricus sylvaticus \\
Pancreatic cancer & Lentinan/Lentinula edodes \\
Bone, brain, liver, breast, gastric, lung, leukemia & Lentinan/Lentinula edodes \\
Cervix, endometrium, ovarian cancer & Maitake/Grifola frondosa \\
Bladder cancer & Agaricus blazei \\
Breast & Maitake/Grifola frondosa \\
& Maitake/Grifola frondosa \\
Cervical & Agaricus sylvaticus \\
& Schizophyllan/ \\
Ovarian & Schizophyllum commune \\
Neck and head & Agaricus blazei \\
& Schizophyllan/ \\
\hline
\end{tabular}

pharmaceuticals to support therapy of many communicable and non-communicable diseases [for review see (43)].

Glucans were also found to be active in the reduction of intestinal injury (44), in protection against liver injury (45), in regulation of hematopoiesis of patients with cancer (46), and in the improvement of benign hyperplasia of the prostate (9). Because glucans have been shown to stimulate the immune system directly, they can be useful in alleviating the symptoms of inflammatory conditions such as irritable bowel syndrome (47).
Glucans can also act as potent antioxidative agents, which lower oxidative stress, particularly in the endothelium. Oxidative stress causes the dysfunction of mitochondrial respiration chain, leading to damage to various tissues including endothelia. Endothelial dysfunction begins with imbalance of oxidant and antioxidants and results in atherosclerosis (48). Sargovo et al. demonstrated that application of glucans from the mushroom Ganoderma lucidum, which has been used for millennia in China (ling zhi) and Japan (reishi), significantly reduced pro-oxidative 


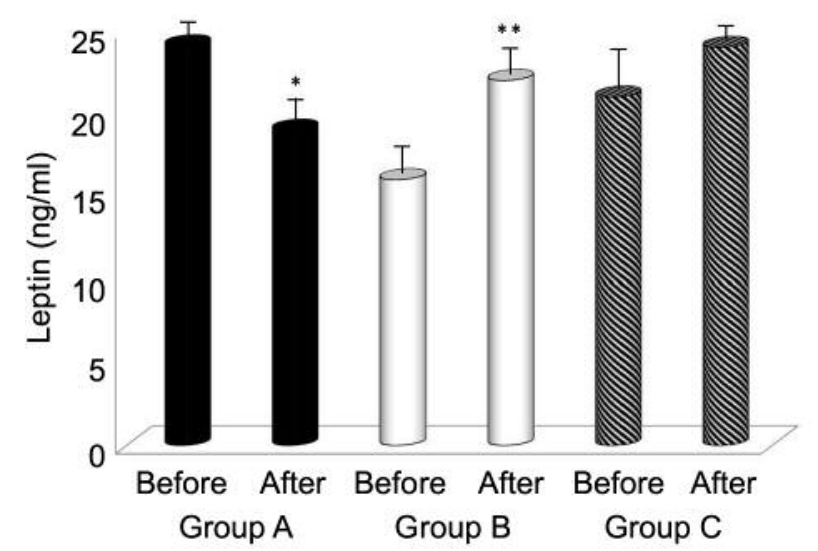

Figure 3. Effect of glucan and vitamin D supplementation on leptin levels. Groups of 72 patients received supplementation with vitamin $D$ and $\beta$ glucan (group A), vitamin D and placebo (group B), or vitamin D alone (group C) for 3 months. The serum level $(\mathrm{ng} / \mathrm{ml})$ of leptin was measured at the start and end of supplementation. In group $A$, the results were significant at $p<0.05$ level $(*)$, at Group $B$ the differences were significant at $p<0.001$ level (**). The differences in group $C$ were not significant.

status in both patients with high-risk and those with stable angina pectoris, and improved endothelial function (49).

Our own studies focused on the possible effects of glucan in children suffering from chronic respiratory disease. Using Transfer Point Glucan \#300, we found that short-term (30-day) oral application of $100 \mathrm{mg} /$ day of glucan resulted in significant improvements of calprotectin, albumin, and lysozyme levels. Direct measurements of salivary immunoglobulins found strong stimulation of IgA (Figure 2A) and IgM production (Figure 2B). In addition, we found levels of exhaled nitric oxide to be depressed and physical endurance significantly improved (10, 50), leading to the conclusion that this type of food supplementation represents a highly promising and inexpensive tool for treatment of chronic respiratory problems in children.

We also focused on the possible effects of glucan supplementation in patients with diabetic retinopathy, which is a common complication of both types of diabetes, affecting the eyes and often leading to blindness. We used a combination of glucan and vitamin D and found significant reduction of body weight, which correlated with reduced levels of leptin (Figure 3 ). We concluded that feeding with the glucan-vitamin D combination affects levels of leptin, apolipoproteins, and general nutrition in patients with diabetic retinopathy $(51,52)$. Additional findings showing significantly reduced orosomucoid levels at the end of a 3-month treatment indicate that continual supplementation with glucans is necessary for patients with diabetes and diabetic retinopathy. We understand that in a population with poor dietary habits, this might be difficult. The direct addition of glucan and fiber into some foodstuffs could represent a solution to this problem.

\section{Conclusion}

In short, glucans have clearly demonstrated an ability to significantly influence various biological reactions. The main focus of the scientific community has been on immune reactions, but other areas, such as cholesterol improvements and diabetic retinopathy, have shown the positive effects of glucan supplementation. Based on the studies mentioned in this review, we propose that oral application of high-quality glucan would constitute a novel approach to rationally enhance various aspects of immune reactions.

\section{Conflicts of Interest}

The Authors declare no conflicts of interests and have no affiliation with any product mentioned in this review.

\section{Authors' Contributions}

All Authors contributed equally to the preparation of this review.

\section{Acknowledgements}

The study was supported by Grant No. RVO 61388971.

\section{References}

1 Wasser SP: Medicinal mushrooms as a source of antitumor and immunomodulating polysaccharides. Appl Microbiol Biotechnol 60(3): 258-274, 2002. PMID: 12436306. DOI: 10.1007/s00253002-1076-7

2 Zipfel C and Robatzek S: Pathogen-associated molecular pattern-triggered immunity: Veni, vidi...? Plant Physiol 154(2): 551-554, 2010. DOI: 10.1104/pp.110.161547

3 Bohn JA and BeMiller JN: $(1 \rightarrow 3)-\beta$-D-glucans as biological response modifiers: A review of structure-functional activity relationships. Carbohydr Polym 28(1): 3-14, 1995. DOI: 10.1016/0144-8617(95)00076-3

4 Novak $M$ and Vetvicka V: Glucans as biological response modifiers. Endocr Metab Immune Disord Drug Targets 9(1): 6775, 2009. PMID: 19275682.

5 Torrence PF: Biological Response Modifiers: New Approaches to Disease Intervention. Academic Press: Orlando, 1985.

6 Vetvicka V and Novak M: Biology and Chemistry of Betaglucan: Beta-glucan, Structure, Chemistry and Specific Application. Bentham Science Publishers: Oak Park, 2013.

7 Shear MJ, Turner FC, Perrault A and Shovelton T: Chemical treatment of tumors. V. Isolation of the hemorrhage-producing fraction from Serratia marcescens (Bacillus prodigiosus) culture filtrate. J Natl Cancer Inst 4(1): 81-97, 1943. DOI: 10.1093/ jnci/4.1.81

8 Pillemer L, Schoenberg MD, Blum L and Wurz L: Properdin system and immunity. II. Interaction of the properdin system with polysaccharides. Science 122(3169): 545-549, 1955. PMID: 13255887.

9 Vetvicka V and Vetvickova J: Anti-stress action of an orallygiven combination of resveratrol, beta-glucan, and vitamin $\mathrm{C}$. 
Molecules 19(9): 13724-13734, 2014. PMID: 25255758. DOI: 10.3390/molecules 190913724

10 Vetvicka V, Richter J, Svozil V, Rajnohova Dobiasova L and Kral V: Placebo-driven clinical trials of Transfer Point Glucan \#300 in children with chronic respiratory problems: Antibody production. Am J Immunol 9(2): 43-47, 2013. DOI: 10.3844/ajisp.2013.43.47

11 Dawood MAO, Eweedah NM, Moustafa EM and Shahin MG: Synbiotic effects of Aspergillus oryzae and beta-glucan on growth and oxidative and immune responses of nile tilapia, Oreochromis niloticus. Probiotics Antimicrob Proteins, 2019 PMID: 30617951. DOI: 10.1007/s12602-018-9513-9

12 Mukhopadhya A, O'Doherty JV and Sweeney T: A combination of yeast beta-glucan and milk hydrolysate is a suitable alternative to zinc oxide in the race to alleviate post-weaning diarrhoea in piglets. Sci Rep 9(1): 616, 2019. DOI: 10.1038/s41598-018-37004-9

13 Vetvicka V and Sima P: $\beta$-Glucan in invertebrates. Invertebrate Survival J 1: 60-65, 2004.

14 Anusuya S and Sathiyabama M: Foliar application of beta-Dglucan nanoparticles to control rhizome rot disease of turmeric Int J Biol Macromol 72: 1205-1212, 2015. PMID: 25450542. DOI: $10.1016 /$ j.ijbiomac.2014.10.043

15 Menard R, de Ruffray P, Fritig B, Yvin JC and Kauffmann S: Defense and resistance-inducing activities in tobacco of the sulfated beta-1,3 glucan PS3 and its synergistic activities with the unsulfated molecule. Plant Cell Physiol 46(12): 1964-1972, 2005. PMID: 16215271 . DOI: $10.1093 / \mathrm{pcp} / \mathrm{pci} 212$

16 Nakao I, Uchino H, Orita K, Kaido I, Kimura T, Goto Y, Kondo T, Takino T, Taguchi T, Nakajima T, Fujimoto S, Miyazaki T, Miyoshi A, Yachi A, Yoshida K, Ogawa N and Furue H: Clinical evaluation of schizophyllan (SPG) in advanced gastric cancer a randomized comparative study by an envelope method. Gan To Kagaku Ryoho 10(4 Pt 2): 1146-1159, 1983 (in Japanese). PMID: 6223584.

17 Bouike G, Nishitani Y, Shiomi H, Yoshida M, Azuma T, Hashimoto T, Kanazawa K and Mizuno M: Oral treatment with extract of Agaricus blazei murill enhanced TH1 response through intestinal epithelial cells and suppressed ova-sensitized allergy in mice. Evid Based Complement Alternat Med 2011: 532180, 2011. PMID: 20953432. DOI: $10.1155 / 2011 / 532180$

18 Hong F, Hansen RD, Yan J, Allendorf DJ, Baran JT, Ostroff GR and Ross GD: Beta-glucan functions as an adjuvant for monoclonal antibody immunotherapy by recruiting tumoricidal granulocytes as killer cells. Cancer Res 63(24): 9023-9031, 2003. PMID: 14695221.

19 Hong F, Yan J, Baran JT, Allendorf DJ, Hansen RD, Ostroff GR, Xing PX, Cheung NK and Ross GD: Mechanism by which orally administered beta-1,3-glucans enhance the tumoricidal activity of antitumor monoclonal antibodies in murine tumor models. J Immunol 173(2): 797-806, 2004. PMID: 15240666. DOI: 10.4049/jimmunol.173.2.797

20 Malyarenko OS, Usoltseva RV, Zvyagintseva TN and Ermakova SP: Laminaran from brown alga Dictyota dichotoma and its sulfated derivative as radioprotectors and radiosensitizers in melanoma therapy. Carbohydr Polym 206: 539-547, 2019. PMID: 30553355. DOI: 10.1016/j.carbpol.2018.11.008

21 Ross GD, Vetvicka V, Yan J, Xia Y and Vetvickova J: Therapeutic intervention with complement and beta-glucan in cancer. Immunopharmacology 42(1-3): 61-74, 1999. PMID: 10408367. DOI: 10.1016/S0162-3109(99)00013-2
22 Vannucci L, Sima P, Vetvicka V and Krizan J: Lentinan properties in anticancer therapy: A review on the last 12-year literature. Am J Immunol 13(1): 50-61, 2017. DOI: 10.3844/ ajisp.2017.50.61

23 Fortin O, Aguilar-Uscanga BR, Vu KD, Salmieri S and Lacroix M: Effect of saccharomyces boulardii cell wall extracts on colon cancer prevention in male F344 rats treated with 1,2dimethylhydrazine. Nutr Cancer 70(4): 632-642, 2018. PMID: 29697280. DOI: $10.1080 / 01635581.2018 .1460672$

$24 \mathrm{Xu} \mathrm{H}$, Zou S and Xu X: The beta-glucan from Lentinus edodes suppresses cell proliferation and promotes apoptosis in estrogen receptor positive breast cancers. Oncotarget 8(49): 86693-86709, 2017. PMID: 29156828. DOI: 10.18632/oncotarget.21411

25 Vetvicka V: $\beta$-Glucans as Natural Biological Response Modifiers. Nova Science Publishers: New York, 2013.

26 Brown L, Rosner B, Willett WW and Sacks FM: Cholesterollowering effects of dietary fiber: A meta-analysis. Am J Clin Nutr 69(1): 30-42, 1999. PMID: 9925120. DOI: 10.1093/ ajcn/69.1.30

27 Phillips GO and Cui SW: An introduction: Evolution and finalisation of the regulatory definition of dietary fibre. Food Hydrocolloids 25(2): 139-143, 2011. DOI: 10.1016/j.foodhyd. 2010.04.011

28 Anderson JW, Baird P, Davis RH Jr., Ferreri S, Knudtson M, Koraym A, Waters V and Williams CL: Health benefits of dietary fiber. Nutr Rev 67(4): 188-205, 2009. PMID: 19335713. DOI: $10.1111 /$ j.1753-4887.2009.00189.x

29 Cheung PCK: Mini-review on edible mushrooms as source of dietary fiber: Preparation and health benefits. Food Sci Hum Wellness 2(3): 162-166, 2013. DOI: 10.1016/j.fshw.2013.08.001

30 Zacherl C, Eisner P and Engel K-H: In vitro model to correlate viscosity and bile acid-binding capacity of digested watersoluble and insoluble dietary fibres. Food Chem 126(2): 423428, 2011. DOI: 10.1016/j.foodchem.2010.10.113

31 Steinberg GR and Kemp BE: AMPK in health and disease. Physiol Rev 89(3): 1025-1078, 2009. PMID: 19584320. DOI: 10.1152/physrev.00011.2008

32 Di Luzio NR and Riggi SJ: The effects of laminarin, sulfated glucan and oligosaccharides of glucan on reticuloendothelial activity. J Reticuloendothel Soc 8(5): 465-473, 1970. PMID: 5471976.

33 Williams DL, Al-Tuwaijri A and Di Luzio NR: Influence of glucan on experimental infections in mice. Int J Immunopharmacol 2(3): 189, 1980. DOI: 10.1016/0192-0561(80)90113-7

34 Quinn PJ: Mechanisms of action of some immunomodulators used in veterinary medicine. Adv Vet Sci Comp Med 35: 43-99, 1990. PMID: 2284999.

35 Vetvicka V, Thornton BP and Ross GD: Soluble beta-glucan polysaccharide binding to the lectin site of neutrophil or natural killer cell complement receptor type 3 (CD11b/CD18) generates a primed state of the receptor capable of mediating cytotoxicity of IC3B-opsonized target cells. J Clin Invest 98(1): 50-61, 1996. PMID: 8690804. DOI: 10.1172/JCI118777

36 Vannucci L, Krizan J, Sima P, Stakheev D, Caja F, Rajsiglova L, Horak V and Saieh M: Immunostimulatory properties and antitumor activities of glucans (review). Int J Oncol 43(2): 357364, 2013. PMID: 23739801. DOI: 10.3892/ijo.2013.1974

37 Sima P, Vannucci L and Vetvicka V: Effects of glucan on bone marrow. Ann Transl Med 2(2): 18, 2014. PMID: 25332994. DOI: 10.3978/j.issn.2305-5839.2014.01.06 
38 Chihara G, Maeda Y, Hamuro J, Sasaki T and Fukuoka F: Inhibition of mouse sarcoma 180 by polysaccharides from Lentinus edodes (Berk.) Sing. Nature 222(5194): 687-688, 1969. PMID: 5768289.

39 Chihara G, Maeda YY and Hamuro J: Current status and perspectives of immunomodulators of microbial origin. Int $\mathrm{J}$ Tissue React 4(3): 207-225, 1982. PMID: 6815071.

40 Vetvicka V and Vetvickova J: $\beta$-1,3-Glucan in cancer treatment. Am J Immunol 8(2): 38-43, 2012. DOI: 10.3844/ ajavsp.2012. 38.43

41 Aleem E: Beta-glucans and their applications in cancer therapy: Focus on human studies. Anticancer Agents Med Chem 13(5): 709-719, 2013. PMID: 23140353.

42 Bell S, Goldman VM, Bistrian BR, Arnold AH, Ostroff G and Forse RA: Effect of beta-glucan from oats and yeast on serum lipids. Crit Rev Food Sci Nutr 39(2): 189-202, 1999. PMID: 10198754. DOI: $10.1080 / 10408399908500493$

43 Mälkki Y and Virtanen E: Gastrointestinal effects of oat bran and oat gum: A review. LWT - Food Sci Technol 34(6): 337-347, 2001. DOI: $10.1006 /$ fstl.2001.0795

44 Vetvicka V, Arriola J, Kaveti A and Dvorak B: Yeast derived $\beta$ glucan reduces intestinal injury in rat model of necrotizing enterocolitis. Int Clin Pathol J 1, 2015. DOI: 10.15406/ icpjl. 2015.01.00017

45 Vetvicka V, Garcia-Mina JM and Yvin JC: Prophylactic effects of humic acid\&glucan combination against experimental liver injury. J Intercult Ethnopharmacol 4(3): 249-255, 2015. DOI: $10.5455 /$ jice. 20150519103113

46 Vetvicka V, Richter J, Kral V, Rajnohova Dobiasova L, Stiborova I and Pohorska J: Regulation of hematopoiesis in cancer patients: Placebo-driven, double-blind clinical trials of $\beta$ glucan. J Tumor 3(1): 305-308, 2015.

47 Parisi GC, Zilli M, Miani MP, Carrara M, Bottona E, Verdianelli G, Battaglia G, Desideri S, Faedo A, Marzolino C, Tonon A, Ermani $\mathrm{M}$ and Leandro G: High-fiber diet supplementation in patients with irritable bowel syndrome (IBS): A multicenter, randomized, open trial comparison between wheat bran diet and partially hydrolyzed guar gum (PHGG). Dig Dis Sci 47(8): 1697-1704, 2002. PMID: 12184518.
48 Bonomini F, Tengattini S, Fabiano A, Bianchi R and Rezzani R: Atherosclerosis and oxidative stress. Histol Histopathol 23(3): 381-390, 2008. PMID: 18072094. DOI: 10.14670/HH-23.381

49 Sargowo D, Ovianti N, Susilowati E, Ubaidillah N, Widya Nugraha A, Vitriyaturrida, Siwi Proboretno K, Failasufi M, Ramadhan F, Wulandari H, Waranugraha Y and Hayuning Putri D: The role of polysaccharide peptide of Ganoderma lucidum as a potent antioxidant against atherosclerosis in high risk and stable angina patients. Indian Heart J 70(5): 608-614, 2018. PMID: 30392496. DOI: 10.1016/j.ihj.2017.12.007

50 Richter J, Svozil V, Kral V, Rajnohova Dobiasova L and Vetvicka V: Beta-glucan affects mucosal immunity in children with chronic respiratory problems under physical stress: Clinical trials. Ann Transl Med 3(4): 52, 2015. DOI: 10.3978/j.issn.23055839.2015.03.20

51 Richter J, Zavorkova M, Vetvicka V, Liehneova I, Kral V and Stiborova I: Vitamin D and $\beta$-glucan supplementation affects levels of leptin, apolipoproteins and general nutrition state in patients with diabetic retinopathy. Edorium J Pathol 5: 1-7, 2018. DOI: $10.5348 / 100009$ P03RJ2018OA

52 Zavorkova M, Vetvicka V, Richter J, Kral V, Liehnova I and Rajnohova DL: Effects of glucan and vitamin d supplementation on obesity and lipid metabolism in diabetic retinopathy. Open Biochem J 12: 36-45, 2018. PMID: 29760812. DOI: 10.2174/ $1874091 \mathrm{X} 01812010036$ 